\title{
Revisão Sistemática e Bibliometria facilitadas por um Canvas para visualização de informação
}

\author{
Canvas for Systematic review and Bibliometrics: literature \\ review facilitated by information visualization
}

Ivan L. de Medeiros, Alessandro Vieira, Gilson Braviano, Berenice S. Gonçalves

Revisão Sistemática, Pesquisa bibliométrica, Visualização de Informação
Systematic Review; Bibliometric research; Information Visualization
A pesquisa por referências bibliográficas, parte fundamental do trabalho acadêmico, demanda rigor em termos de busca, seleção e tratamento de dados. Contribuem, neste processo, a revisão sistemática e a análise bibliométrica de literatura, com o propósito de integrar protocolos quantitativos para pesquisas de referências. Tais métodos de pesquisa, comuns na área da Saúde e da Engenharia, são ainda pouco difundidos em Ciências Humanas e Sociais aplicadas. Neste sentido, o presente artigo objetiva apresentar os procedimentos de revisão sistemática e análise bibliométrica para o público ainda não familiarizado com estes; e propor um processo de pesquisa adaptado, através de Visualização de Informação, para tornar os procedimentos e seus resultados de mais fácil compreensão. Partindo de uma revisão de literatura, foi desenvolvido pelos autores um processo de revisão sistemática e análise bibliométrica baseado no método Proknow-C, desenvolvido na UFSC. Também constam como resultados deste trabalho instrumentos visuais testados em uma oficina na Semana de Pesquisa e Extensão de 2014, da UFSC: um Canvas e um Quadro-Síntese de processo de revisão bibliográfica e bibliometria.

The search for references is fundamental part of academic work. It demands rigor in terms of search, selection and data processing. In view of this it came the systematic review and the bibliometric analysis, with the purpose of integrating quantitative protocols for references research. Such research methods, common in Health and Engineering, are still not widespread in human and social sciences. This paper aims: 1) Provide procedures for systematic review and bibliometric analysis for the novice public with this subject; 2) Provide an adapted research process through Information Visualization, to make the procedures and results easier to understand. From a literature review, it was developed by the authors a process of systematic review and bibliometric analysis based on Proknow-C, a method developed at UFSc. Also listed as results a set of visual instruments tested in a workshop in the Research and Extension Week at UFSC, in 2014: a Canvas and a Checklist of bibliographic and bibliometric review process. 


\section{Introdução}

Em todo projeto científico, se faz necessária uma pesquisa bibliográfica como fundamento para a criação de novos conhecimentos. Dentre os possíveis objetivos das pesquisas bibliográficas, temos: o levantamento dos pareceres de outros pesquisadores sobre o estudo a ser pesquisado; a identificação de lacunas investigativas; a utilização, como material de estudo, dos trabalhos desenvolvidos por outros pesquisadores; etc. Contudo, a quantidade de publicações nos campos de pesquisa oferece desafios em termos de coleta e seleção criteriosa.

Surge, assim, uma problemática comum a pesquisadores de diversas áreas, entre elas, o Design, que é encontrar publicações pertinentes à sua pesquisa, selecioná-las a partir de critérios confiáveis, tratar os dados e usar as informações obtidas em seus projetos.

Para tratar tais desafios, pode-se usar um peculiar tipo de pesquisa bibliográfica, conhecido como Revisão Sistemática, bem como as técnicas de Análise Bibliométrica. Através desses procedimentos quantitativos de pesquisa, pode-se diminuir a subjetividade na escolha das publicações e promover seleções e tratamentos mais confiáveis de dados baseados em protocolos replicáveis e indicadores quantitativos. Este trabalho se caracteriza como pesquisa exploratória, como afirma Gil (2008), por ter como finalidade esclarecer conceitos e ideias, envolvendo um levantamento bibliográfico sobre determinado assunto, tendo como meta um problema melhor definido, passível de investigações mais sistematizadas.

Nesse contexto, o presente artigo tem por objetivos:

a) apresentar um método de revisão sistemática e análise bibliométrica desenvolvido por seus autores a partir de uma adaptação e simplificação do ProKnow-C (Knowledge Development Process - Constructivist), o qual foi desenvolvido pelo LabMCDA UFSC (ENSSLIN et al. 2010) e testado em uma oficina de extensão universitária na UFSC, em 2014;

b) fazer uso de uma técnica de representação visual do tipo Canvas, a fim de facilitar a compreensão do processo desenvolvido, tornando assim o processo de revisão sistemática e análise bibliométrica mais acessível através de Gestão Visual.

O presente estudo parte do pressuposto de que a Visualização de Informação é importante em diversos tipos de pesquisas. Desse fato decorre que procedimentos bibliométricos e afins podem ser mais facilmente compreendidos e utilizados, quando a visualização da comunicação possibilitar maior estabilização e alinhamento do processo quanto aos interesses. Sendo assim, este trabalho evidencia a Gestão Visual de um processo de revisão sistemática e análise bibliométrica desenvolvido pelos autores, sem cobrir todas as variações possíveis desses procedimentos, nem todas as formas de representá-los graficamente para melhor compreensão das informações. 


\section{Fundamentação teórica}

\subsection{Pesquisa Bibliográfica e Revisão Sistemática}

\subsubsection{Revisão de literatura como fundamento de pesquisa}

A pesquisa bibliográfica compreende uma investigação acerca de assuntos semelhantes àquele que esta sendo investigado, sendo uma das primeiras etapas do método científico, contribuindo para evitar a ocorrência da duplicidade de trabalhos.

Para Marconi e Lakatos (2003), nenhuma pesquisa da atualidade parte do zero; alguém ou algum grupo, em uma localidade, já pode ter feito pesquisa igual ou semelhante, ou até realizado algum trabalho que possa complementar a pesquisa pretendida. Devido a isso, uma busca em tais fontes torna-se imprescindível, com o intuito de não duplicar esforços, minimizando trabalho acerca de ideias já expressas. Gil (2002) afirma que a principal vantagem da pesquisa bibliográfica está no fato de permitir ao pesquisador a cobertura de uma gama de fenômenos muito mais ampla do que aquela que este poderia pesquisar diretamente. Segundo Lakatos (1992, p.44), "a pesquisa bibliográfica pode, portanto, ser considerada também como o primeiro passo de toda pesquisa científica”..

É comum, porém, a pesquisa bibliográfica se deparar com um problema grave: o levantamento apenas de referências conhecidas pelo pesquisador, ou aquelas de sua preferência e repertório, o que implica, muitas vezes, na limitação da revisão de literatura.

\subsubsection{Revisão Sistemática}

Para resolver os problemas comuns da pesquisa bibliográfica, trazendo mais confiabilidade à mesma, foram desenvolvidos procedimentos mais criteriosos, conhecidos com o termo Revisão Sistemática. Sampaio e Mancini (2007) definem a Revisão Sistemática como sendo um tipo de pesquisa que utiliza como fonte de dados a literatura sobre determinado tema. Esse tipo de investigação disponibiliza um resumo das evidências relacionadas a uma estratégia de intervenção específica, mediante a aplicação de métodos explícitos e sistematizados da busca, apreciação crítica e síntese da informação selecionada. Os autores ainda definem a revisão como sendo composta de cinco passos, apresentados no Quadro 1: 
Quadro 1 Passos da Revisão Sistemática.

Fonte: adaptado de Sampaio e Mancini (2007)

\begin{tabular}{|l|l|}
\hline Passos & Descrição \\
\hline Passo 1: Definindo a pergunta & $\begin{array}{l}\text { O primeiro passo a ser dado no início de } \\
\text { qualquer estudo é estabelecer o que se } \\
\text { deseja pesquisar. Questões mal formuladas } \\
\text { podem conduzir a decisões obscuras sobre o } \\
\text { que incluir na revisão posteriormente. }\end{array}$ \\
\hline Passo 2: Buscando a evidência & $\begin{array}{l}\text { Esta etapa realiza-se em bases de dados } \\
\text { eletrônicas (databases) indexadas (a } \\
\text { partir da seleção de unitermos, também } \\
\text { conhecidos como descritores construídos } \\
\text { com as palavras-chave e operadores } \\
\text { booleanos AND, NOT, OR etc.). }\end{array}$ \\
\hline Passo 3: Revisando e selecionando os & $\begin{array}{l}\text { De posse de todos os estudos a serem } \\
\text { incluídos, são estabelecidos critérios } \\
\text { para determinar a sua validade e se há } \\
\text { possibilidade dos resultados possuírem } \\
\text { vieses. }\end{array}$ \\
\hline Passo 4: Analisando a qualidade & $\begin{array}{l}\text { Com base nas semelhanças entre artigos, } \\
\text { os dados serão agrupados para a obtenção } \\
\text { das conclusões finais (ou da metanálise, } \\
\text { metodológica dos estudos }\end{array}$ \\
$\begin{array}{l}\text { se este for o caso). Cada um destes } \\
\text { agrupamentos deve - preferencialmente - } \\
\text { ser pré-estabelecido previamente, evitando } \\
\text { a tendenciosidade. }\end{array}$ \\
\hline Passo 5: Apresentando os resultados & $\begin{array}{l}\text { Nas etapas finais, a redação dos resultados } \\
\text { deve ser feita levando-se em conta a } \\
\text { questão norteadora estabelecida no } \\
\text { primeiro passo supracitado. }\end{array}$ \\
\hline & \\
& \\
& \\
&
\end{tabular}

\subsubsection{Proknow-C}

O presente estudo se fundamenta no método de revisão sistemática conhecido como Proknow-C (Knowledge Development ProcessConstructivist), desenvolvido e patenteado na UFSC, por Ensslin et al. (2010). Segundo Lacerda el al. (2012, p.64), o Proknow-C:

"inicia pelo interesse do pesquisador sobre um determinado tema, bem como suas delimitações e restrições intrínsecas ao contexto acadêmico, em busca da construção do conhecimento no pesquisador, a fim de que ele possa iniciar uma pesquisa científica com fundamentação."

Este método, desenvolvido para a seleção dos artigos mais relevantes sobre o tema de interesse do pesquisador, foi idealizado para possibilitar a realização de uma análise a fim de averiguar os principais trabalhos, autores e periódicos que publicaram sobre o tema de interesse. Além da seleção dos artigos para compor um referencial teórico, o processo evidencia também a possibilidade de uma análise bibliométrica, a qual hierarquiza os periódicos que mais se 
destacam quanto a publicações sobre o tema. Através do ProKnow-C é possível selecionar e evidenciar artigos, autores e periódicos na área e construir, desta maneira, o arcabouço teórico dos trabalhos acadêmicos e científicos mais relevantes para a pesquisa de interesse. (LACERDA, ELSSLIN e ELSSLIN, 2012)

\subsection{Análise bibliométrica}

\subsubsection{Definição de Bibliometria}

Os congressos e revistas científicas são os canais midiáticos mais adequados e rápidos utilizados para publicar pesquisas de reconhecido valor para a sociedade acadêmica. Visto que a avaliação da importância dessas publicações para uma determinada pesquisa não é uma tarefa fácil, existe, há algumas décadas, na comunidade acadêmica, a preocupação acerca da mensuração do valor científico de publicações enquanto referências bibliográficas. Tal interesse deu origem à Bibliometria.

Pao (1989), em seu livro Concepts of Information Retrieval, apresenta a Bibliometria como um termo colocado por Allan Pritchard, em seu artigo Statistical Bibliography or Bibliometrics, publicado em 1969, para denotar a área de estudo que utiliza métodos matemáticos e estatísticos a fim de investigar e quantificar os processos de comunicação escrita. Tague-Sutcliffe (1992) definiu a Bibliometria como sendo o estudo dos aspectos quantitativos da produção científica, a disseminação e o uso da informação publicada e validade. Esta área da ciência desenvolve padrões e modelos estatísticos para medir tais processos.

Após definidas as estratégias de busca de estudos científicos, vem a tarefa de selecionar o material obtido. A fim de facilitar esse processo, há tempos os pesquisadores utilizam “estudos métricos” como ferramenta de análise para avaliar a informação produzida com base em recursos quantitativos. Como exemplo, cita-se o estudo de Narin (NARIN, 1976).

Diante dos achados da revisão sistemática, aplica-se a bibliometria, que, de maneira quantitativa, avalia a relevância das publicações selecionadas através de indicadores e norteia o processo de seleção do referencial bibliográfico que melhor se aproxime do interesse do assunto pesquisado.

\subsubsection{Aplicações da Bibliometria}

Segundo Escorcia (2008, apud Tápanes e Afonso, 2013), a bibliometria oferece informações sobre os resultados do processo 
de investigação, o seu volume, evolução, visibilidade e estrutura, através de uma análise quantitativa de características bibliográficas de um conjunto de publicações, constituindo uma ferramenta para estabelecer indicadores de produção científica de uma instituição em relação ao país e até mesmo os cientistas a respeito de suas próprias comunidades. E este estudo de aspectos quantitativos da produção, disseminação e uso da informação registrada serve para que desenvolvam modelos matemáticos e medidas que, por sua vez, são úteis para prever e tomar decisões sobre estes processos.

Oliveira e Gracio (2011) explicam que os estudos métricos desenvolveram-se a partir da blibliometria e outras abordagens, como a cientometria, webometria, informetria e patentometria, as quais envolvem um amplo conjunto de indicadores bibliométricos.

\subsubsection{Análise por Indicadores Bibliométricos}

Analisar implica, etimologicamente, na quebra de um fenômeno em partes menores. A análise bibliométrica é um tratamento de dados oriundos da revisão sistemática, quebrando esses dados em seus componentes fundamentais, aqui chamados de indicadores bibliométricos. Estes podem ser entendidos como unidades de medida para o tratamento de dados da revisão sistemática. Cada análise bibliométrica começa com a seleção dos indicadores apropriados para realizar seus objetivos.

Com o objetivo de medir, compreender e avaliar os resultados encontrados nas buscas, pesquisadores utilizam técnicas bibliométricas, que são análises quantitativas com fins a mensurar a produção e disseminação científica (ARAÚJO, 2006).

Em termos de Indicadores bibliométricos, destacam-se os de peso do artigo, do periódico, do evento, dos autores etc. Como ilustração da importância da bibliometria, a Figura 1 mostra a evolução histórica, de 2006 a 2013, de três indicadores bibliométricos de um periódico, apresentada em um portal de publicações acadêmicas na internet:

Figura 1 Figura 1 - Exemplo de analise bibliométrica. Fonte: Scielo (2014)

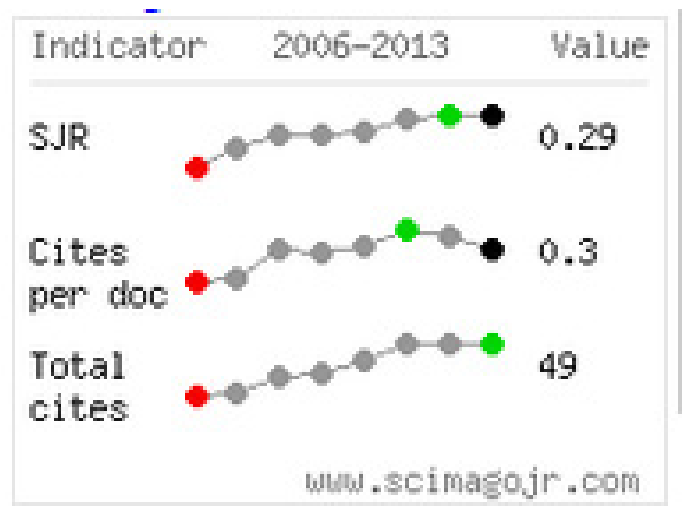


O Quadro 2 apresenta alguns dos indicadores mais usados na comunidade científica internacional.

Quadro 2 Alguns dos principais indicadores bibliométricos.

Fonte: adaptado de Journal Metrics (2014)

\begin{tabular}{|l|l|}
\hline Indicador & Descrição \\
\hline Impact per Publication (IPP) & $\begin{array}{l}\text { Indica o número médio de citação de uma } \\
\text { publicação na revista. }\end{array}$ \\
\hline Source-Normalized Impact per Paper (SNIP) & $\begin{array}{l}\text { Mede o impacto do artigo levando em conta } \\
\text { características do campo de pesquisa, a } \\
\text { frequência de citações, a velocidade com que } \\
\text { o impacto do artigo amadurece etc. }\end{array}$ \\
\hline SciMago Journal Ranking (SJR) & $\begin{array}{l}\text { Mede o prestígio de um periódico levando } \\
\text { em conta indicadores bibliométricos de } \\
\text { artigos que o citam. }\end{array}$ \\
\hline
\end{tabular}

O Quadro 2 cita apenas três dos principais indicadores, porém há uma grande diversidade destes, que devem ser selecionados pelo pesquisador a partir de seus critérios de busca estabelecidos previamente no início da pesquisa.

\subsection{Visualização de Informação e o Uso de Canvas}

\subsubsection{Recursos gráficos para facilitar a compreensão}

Visualização de Informação, também conhecida por Gestão Visual, diz respeito a tratar dados brutos para torná-los mais compreensíveis através de representações gráficas. Esse processo envolve, portanto, tornar informações mais compreensíveis para melhor tomada de decisão. Segundo Vieira \& Correa (2011), o objetivo da construção das visualizações é auxiliar no entendimento de determinado assunto minimizando o esforço cognitivo nessa compreensão, visando à inclusão informacional dos usuários ou consumidores das visualizações.

A Visualização da Informação pode ser feita com computadores e métodos estatísticos, ou simplesmente com recursos gráficos como desenhos a mão, impressos, post-its etc, e costuma envolver apenas o mapeamento visual, como é feita no Design Thinking (Brown, 2010) e em metodologias industriais de Qualidade, como o Kanban e o Lean Management (Pires e Queiroz, 2012).

A Visualização de Informações computadorizada, segundo Card (1999), envolve basicamente três tipos de técnicas: Transformação de dados, Mapeamento visual e transformação visual. As técnicas desse processo são classificáveis em seis categorias (Souza, 2008, p.52): 
- "Visualização de Dados - são as representações visuais de dados quantitativos, que podem ser encontrados nos gráficos de linha, pizza, barra ou áreas.

- Visualização de Informações - trata-se das representações visuais que transformam dados em imagens, por exemplo, os diagramas de fluxo, de entidade relacionamento e as linhas do tempo. Esse método é capaz de ampliar a cognição (conhecimento, percepção) do usuário.

- Visualização Conceitual - representam os conceitos qualitativos, as ideias, os planos e as análises. Os mapas mentais e conceituais e os gráficos de camadas são os exemplos desse método, que são representados por círculos ou caixas conectados a outros elementos formando um relacionamento.

- Visualização Metafórica - utilizam metáforas visuais para representar um conjunto de informações complexas de modo organizado e estruturado.

- Visualização Estratégica - tratam-se das representações visuais utilizadas para a análise, comunicação e desenvolvimento de estratégias em uma organização. Por exemplo: diagrama de ciclo de vida ou de cadeia de valor.

- Visualização Composta - são as representações híbridas”.

\subsubsection{Visualização através de Canvas}

Dentre as técnicas de Visualização da Informação mais usadas, especialmente dentre as que não envolvem meios computadorizadas, está a criação de Canvas, isto é, painéis ou telas. Canvas foram popularizados em empresas por bestsellers como o "Business model generator", ligados à metodologia Lean aplicada em Startup. Segundo Pires e Queiroz (2012, p. 13), um Canvas é "uma ferramenta para descrever, analisar e construir modelos de negócio, e que relaciona graficamente os chamados Nove Blocos de Construção do Modelo de Negócio”.

O Canvas é uma técnica de Mapeamento Visual (Card, 1999), que envolve fundamentalmente Visualização Conceitual e Estratégica (Souza, 2008). Esse painéis (Canvas) costumam ser impressos em tamanho grande e colocados em paredes de salas de reuniões, para constante visualização. Eles possuem a função de monitoria dos processos, ajudando os profissionais a checar regularmente os passos que já foram tomados em um processo e os que precisam ser tomados.

A Figura 2 apresenta um exemplo de Canvas, que tem por objetivo sintetizar as principais informações estratégicas sobre um negócio, facilitando a compreensão de uma organização em termos de objetivos, atividades, parceiros, recursos etc. 
Figura 2 Exemplo de Canvas (Fonte: Osterwalder e Pigneur, 2010)

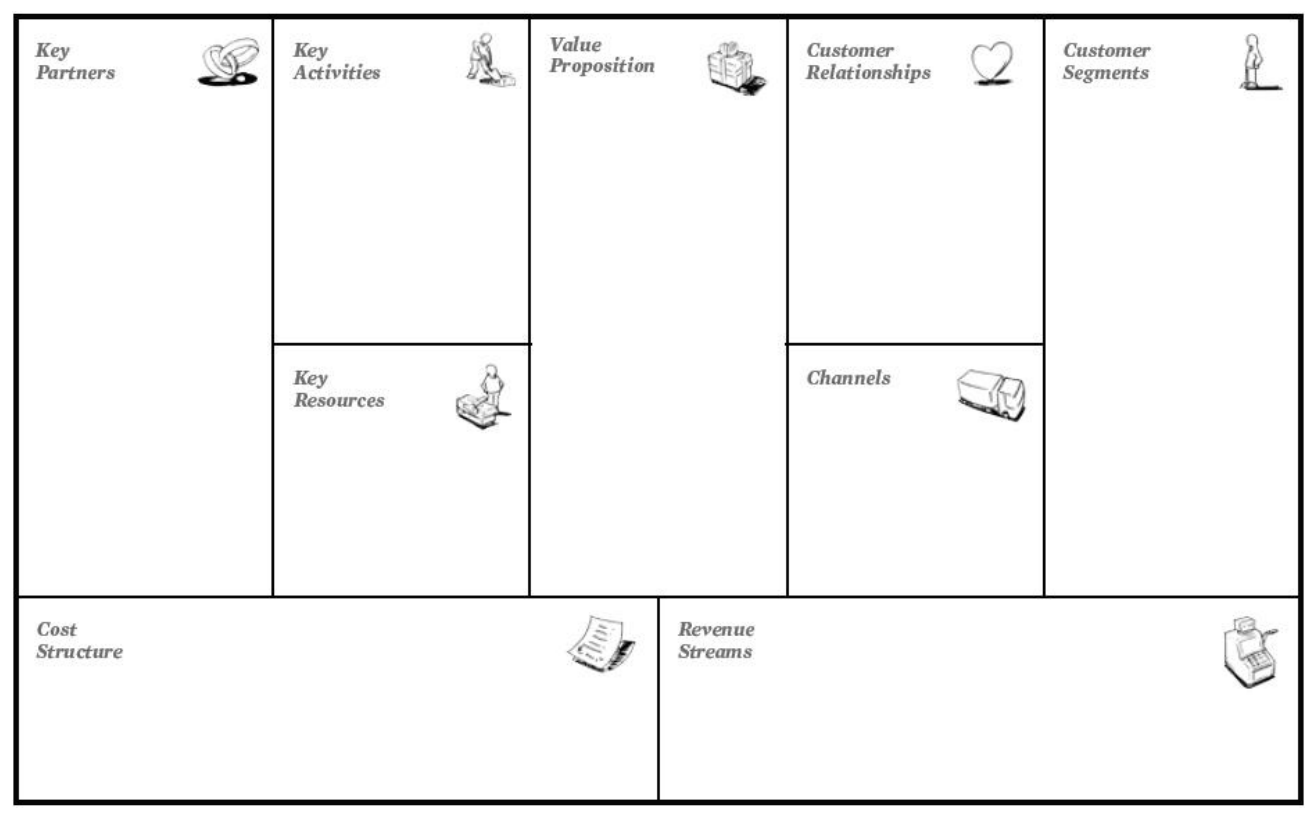

\section{Procedimentos metodológicos}

A partir de uma pesquisa bibliográfica sobre revisão sistemática e bibliometria, com fundamentos no ProKnow-C (Enssilin, 2010), este estudo gerou a primeira versão do processo e dos instrumentos gráficos, como o Canvas. Esta versão foi trabalhada internamente, e testada em uma oficina realizada na Semana de Ensino, Pesquisa e Extensão - SEPEX 2014 da UFSC, evento aberto a comunidade e realizado anualmente no Campus de Florianópolis-SC. Foi escolhido um Canvas inspirado no Business Model Canvas, estruturando em apenas uma tela para visualização imediata, que pode ser impressa em formato A3 e colocada numa parede, facilitando a gestão visual do processo de pesquisa bibliográfica.

A oficina, aberta para alunos de graduação e pós-graduação da UFSC, ocorreu em outubro de 2014 e serviu como prototipagem e avaliação. Participaram dela seis alunas de pós-graduação em Farmácia e Engenharia da Produção, todas já praticantes de procedimentos de revisão sistemática e análise bibliométrica, que, ao final responderam a questionário e participaram de entrevista não estruturada. 


\subsection{Checklist do processo}

Foi apresentado na oficina um checklist para orientar o processo de revisão sistemática e análise bibliométrica, o qual foi refinado com feedbacks. Sua versão final é apresentada no Quadro 3.

Quadro 3 Checklist de revisão sistemática e análise bibliométrica

\begin{tabular}{|c|c|c|}
\hline Etapa & Sub-Etapa & Descrição \\
\hline \multirow{7}{*}{$\begin{array}{l}\text { Revisão } \\
\text { Sistemática }\end{array}$} & 1) Determine seus objetivos & $\begin{array}{l}\text { O que você deseja pesquisar? Qual o tema? Como descrever seu } \\
\text { objeto com palavras-chaves? }\end{array}$ \\
\hline & $\begin{array}{l}\text { 2) Determine um descritor de } \\
\text { busca }\end{array}$ & $\begin{array}{l}\text { Teste os termos componentes do descritor um a um no Google } \\
\text { Scholar antes, para checar se são pertinentes na busca. Depois dos } \\
\text { termos, selecione operadores lógicos para integrá-los, formando } \\
\text { assim o descritor. } \\
\text { Exemplo de Algoritmo de busca: ("tangible interaction" OR "tangible } \\
\text { interface") AND autis* } \\
\text { OBS: "tangible interaction" é um termo, e "AND" e “*” são } \\
\text { operadores lógicos. }\end{array}$ \\
\hline & $\begin{array}{l}\text { 3) Escolha as bases de dados } \\
\text { pertinentes }\end{array}$ & $\begin{array}{l}\text { Selecione-as dentre aquelas disponíveis no Portal de Periódicos } \\
\text { da CAPES. }\end{array}$ \\
\hline & $\begin{array}{l}\text { 4) Realize a busca usando o } \\
\text { descritor }\end{array}$ & Em todas as bases de dados escolhidas na etapa anterior. \\
\hline & $\begin{array}{l}\text { 5) Filtre a busca por critérios } \\
\text { pré-selecionados }\end{array}$ & $\begin{array}{l}\text { Aplique filtros nas buscas feitas na Etapa } 4 \text {. Exemplos de filtros: } \\
\text { a) apenas artigos em periódicos com peer review; } \\
\text { b) apenas publicações entre } 2004 \text { e } 2014 \text {; } \\
\text { c) apenas publicações disponíveis na base da Capes. }\end{array}$ \\
\hline & $\begin{array}{l}\text { 6) Use o EndNOTE (OBS: O } \\
\text { Zotero é uma Alternativa: } \\
\text { Software Livre para o EndNOTE) }\end{array}$ & $\begin{array}{l}\text { Pegue todos os artigos que restaram depois do passo 5, faça } \\
\text { download do arquivo .RIS deles (na base de dados em que o achou). } \\
\text { Pegue esse arquivo .RIS contendo os dados de todos os artigos, } \\
\text { como por exemplo: autores, data e local de publicação, resumo etc. } \\
\text { Abra no software EndNOTE, e selecione os artigos por: } \\
\text { a) título; } \\
\text { b) palavras-chave; } \\
\text { c) resumo. }\end{array}$ \\
\hline & 7) Sistematize a bibliografia & $\begin{array}{l}\text { Faça uma planilha mostrando os artigos que sobraram depois } \\
\text { da etapa 6. Nessa planilha, explicite o autor, ano de publicação, } \\
\text { título, fonte etc, de cada artigo. OBS: Destaque itens da planilha } \\
\text { como "Temas mais frequentes", "Palavras-chaves mais usadas", } \\
\text { "Áreas" etc. }\end{array}$ \\
\hline & $\begin{array}{l}\text { 8) Exponha os indicadores } \\
\text { bibliométricos de cada artigo } \\
\text { na planilha da etapa } 7\end{array}$ & $\begin{array}{l}\text { Selecione os indicadores bibliométricos mais pertinentes para } \\
\text { satisfazer os objetivos de sua revisão (Etapa 1). }\end{array}$ \\
\hline $\begin{array}{l}\text { Análise } \\
\text { Bibliométrica }\end{array}$ & $\begin{array}{l}\text { 9) Monte gráficos para } \\
\text { apresentar os resultados }\end{array}$ & $\begin{array}{l}\text { Crie tabelas e gráficos (histogramas, de pizza, diagramas etc), para } \\
\text { expressar os dados bibliométricos dos artigos. Ex: principais autores, } \\
\text { conexões entre autores via citações, ranking de publicações, regiões } \\
\text { do mundo ou centros de pesquisa mais importantes, timeline de } \\
\text { publicações etc. OBS: seja criativo nesta etapa! }\end{array}$ \\
\hline Resultado Final & 10) Escreva um relatório & $\begin{array}{l}\text { Escreva um texto integrando dados da planilha (Etapa 7) } \\
\text { com os gráficos bibliométricos (Etapa 9), com suas análises e } \\
\text { interpretações. É esse texto, com esses elementos todos, que } \\
\text { embasará sua pesquisa. }\end{array}$ \\
\hline
\end{tabular}


O checklist expresso no Quadro 3 serve como ferramenta de trabalho para o pesquisador verificar, passo o passo, como está se saindo no processo de pesquisa. Contudo, ele se apresenta como informação textual rearranjada visualmente em formato de planilha. Optou-se ainda por uma maneira mais visual de instruir quanto ao processo de pesquisa. Para tal, o Canvas, inspirado no modelo do bestseller "Business Model Generation" (Imagem 2).

O Quadro 3 apresenta uma sequência estruturada que funciona paralelamente ao Canvas para Bibliometria (Figura 3) e nele deve-se seguir as etapas numeradas sequencialmente para se obter um resultado adequado. Na etapa 1 do Canvas e do checklist - Objetivos e metas - , este campo orienta o pesquisador a manter o foco na pesquisa, diretamente relacionado a etapa 2 do Canvas, no qual é necessário descrever o tema da pesquisa de forma clara e objetiva.

Por conseguinte, são selecionadas um grupo de palavraschaves, que devem ser divididas em áreas específicas, conforme o exemplo de montagem de palavras-chaves, ilustrado no Quadro 4. À medida que forem acrescentadas colunas, mais afuniladas ficam a pesquisa, contudo, recomenda-se, no máximo, o uso de três colunas de assunto. A escolha das palavras-chaves é fundamental para a pesquisa ser direcionada e coerente. Recomenda-se que essas palavras sejam testadas isoladamente. Isso pode ser feito de maneira simples e eficiente, no Google Scholar, verificando a quantidade de resultados, fazendo assim um comparativo com os termos mais apropriados para montar o descritor de busca.

Quadro 4 Exemplo de palavras-chaves

\begin{tabular}{lll}
\hline Fishmealprocess & Musculoskeletal & Work \\
\hline Fishprocess & Workload & \\
\hline Fishprocessing & & \\
\hline Fish & \\
\hline Fishmeal & \\
\hline
\end{tabular}

Pode-se ver no Quadro 4 três colunas separadas por áreas de interesse de pesquisa. Essas palavras são a base para a montagem do descritor, conforme exemplo a seguir: (Fishprocessing OR Fishmealprocess OR Fishprocessing OR Fish OR Fishmeal) AND (musculoskeletal OR workload) AND work.

Com esse descritor montado, o pesquisador seleciona as bases de dados relacionadas a sua área de interesse. Para orientar o cientista no campo 5 do Canvas proposto identificaram-se possíveis bases de dados. Da mesma forma, no campo 6 foram listados possíveis filtros aplicados posteriormente a pesquisa na base de dados. Vale lembrar que deve-se utilizar o mesmo descritor em todas as bases de dados selecionadas. Nestas bases são coletados os dados em forma de arquivo ".RIS", cujo pacote de dados é aberto em software como o ENDNOTE e o ZOTERO. 


\subsection{Canvas}

A Figura 3 apresenta o Canvas, já em sua versão final, desenvolvida após a oficina na SEPEX, contemplando novos incrementos:

Figura 3 Versão final do Canvas

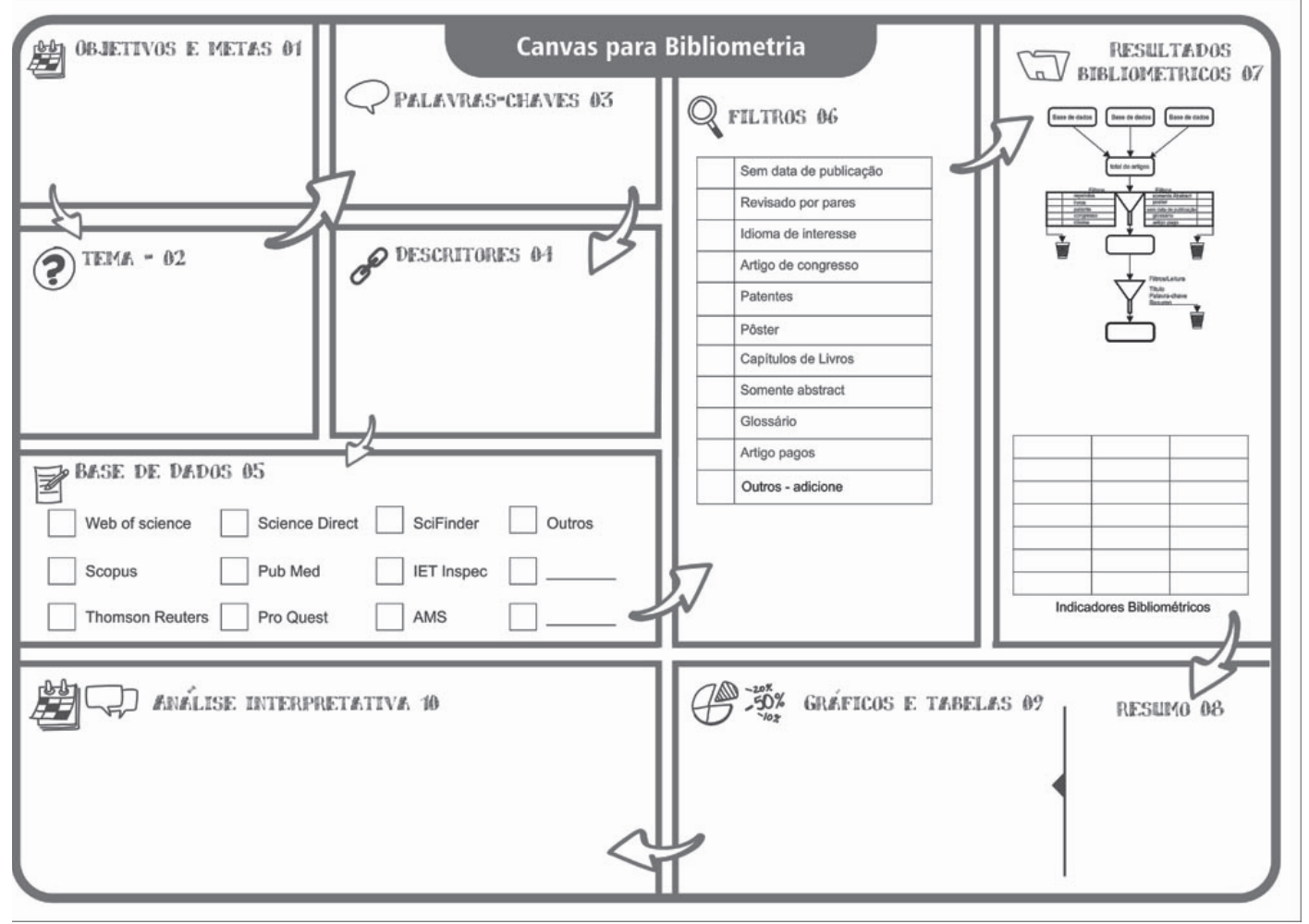

A Figura 3 oferece uma visão global do Canvas, constituído por dez quadros integrados e numerados na sequência cronológica de tarefas: o quadro 01 demanda escrever os objetivos e metas; o quadro 02, descrever o tema da pesquisa com frases; o quadro 03, descrever o tema em palavras-chaves; o quadro 04, transformar as palavraschaves em descritores, isto é, termos com poder de busca em bases de dados indicados no quadro 05; o quadro 06 solicita a seleção de filtros de buscas que serão empregados; o quadro 07 constitui-se de uma planilha que sintetiza os indicadores bibliométricos dos resultados depois da filtragem; o quadro 08 solicita a redação de um resumo textual sobre os resultados; o quadro 09 apresenta a escolha das formas gráficas de representação desses resultados textuais e numéricos; e, finalmente, o quadro 10 constitui-se em uma análise interpretativa dos gráficos e resultados textuais. Recomenda-se a impressão do Canvas em uma folha A3.

Na Figura 4 é possível visualizar com mais detalhes as etapas iniciais de planejamento e estruturação na pesquisa bibliográfica sistematizada. Nessas cinco primeiras fases, o pesquisador planeja as 
suas ações e caminhos de busca. Conforme o usuário do Canvas vai avançando gradativamente cada etapa do processo, e preenchendo os espaços nos campos, sua pesquisa parte de um pensamento subjetivo para um método sistematizado e organizado, gerando um processo científico replicável.

Figura 4 Primeira parte do Canvas

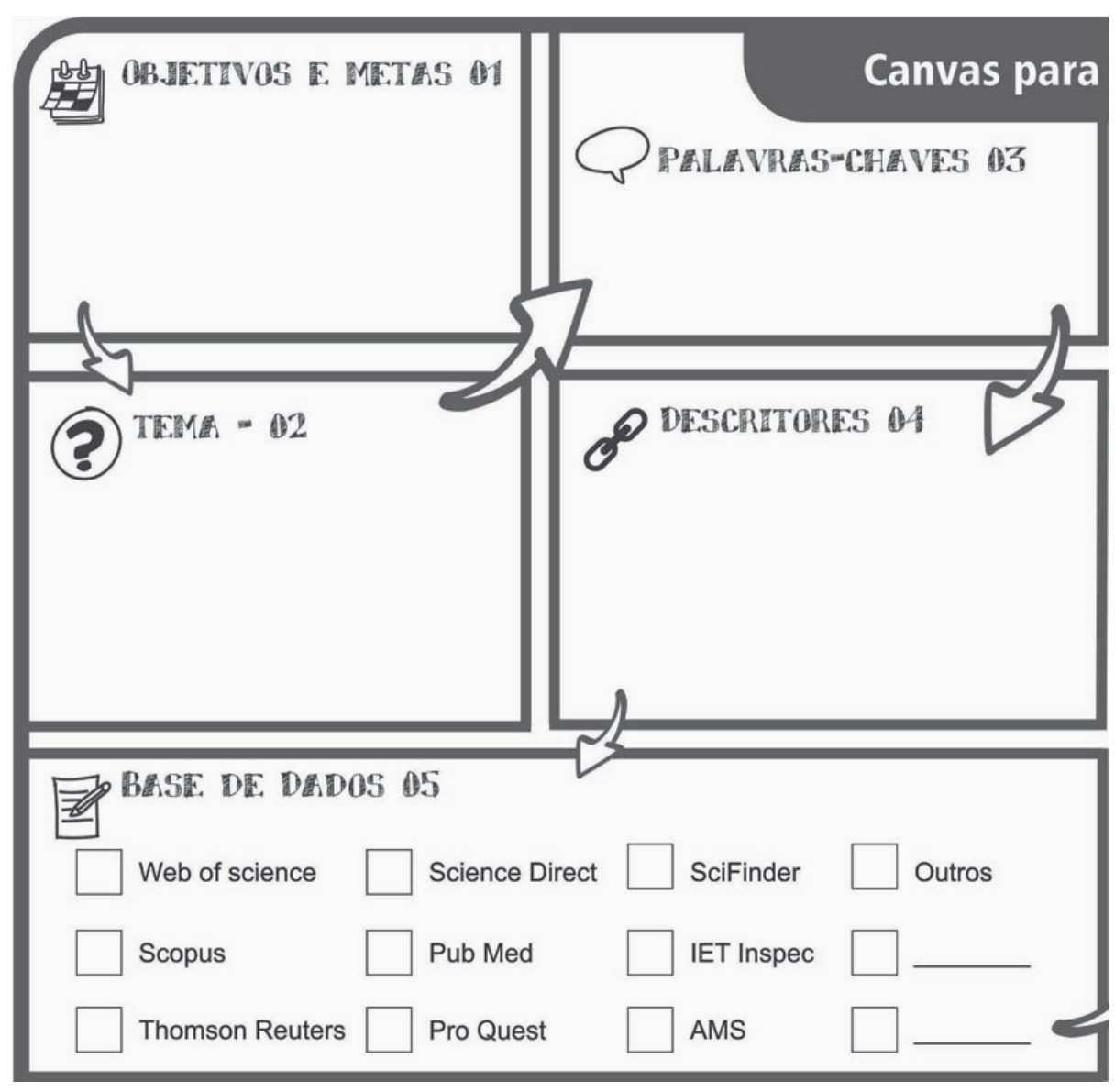

O Canvas para bibliometria foi idealizado para funcionar concomitantemente ao Checklist apresentado no Quadro 3. Seguindo esse raciocínio, o Canvas para Bibliometria possibilita uma visualização sistematizada das ações descritas passo a passo no Checklist. A Figura 5 ilustra com mais detalhes dos quadros seguintes do Canvas. 
Figura 5 Segunda parte do Canvas

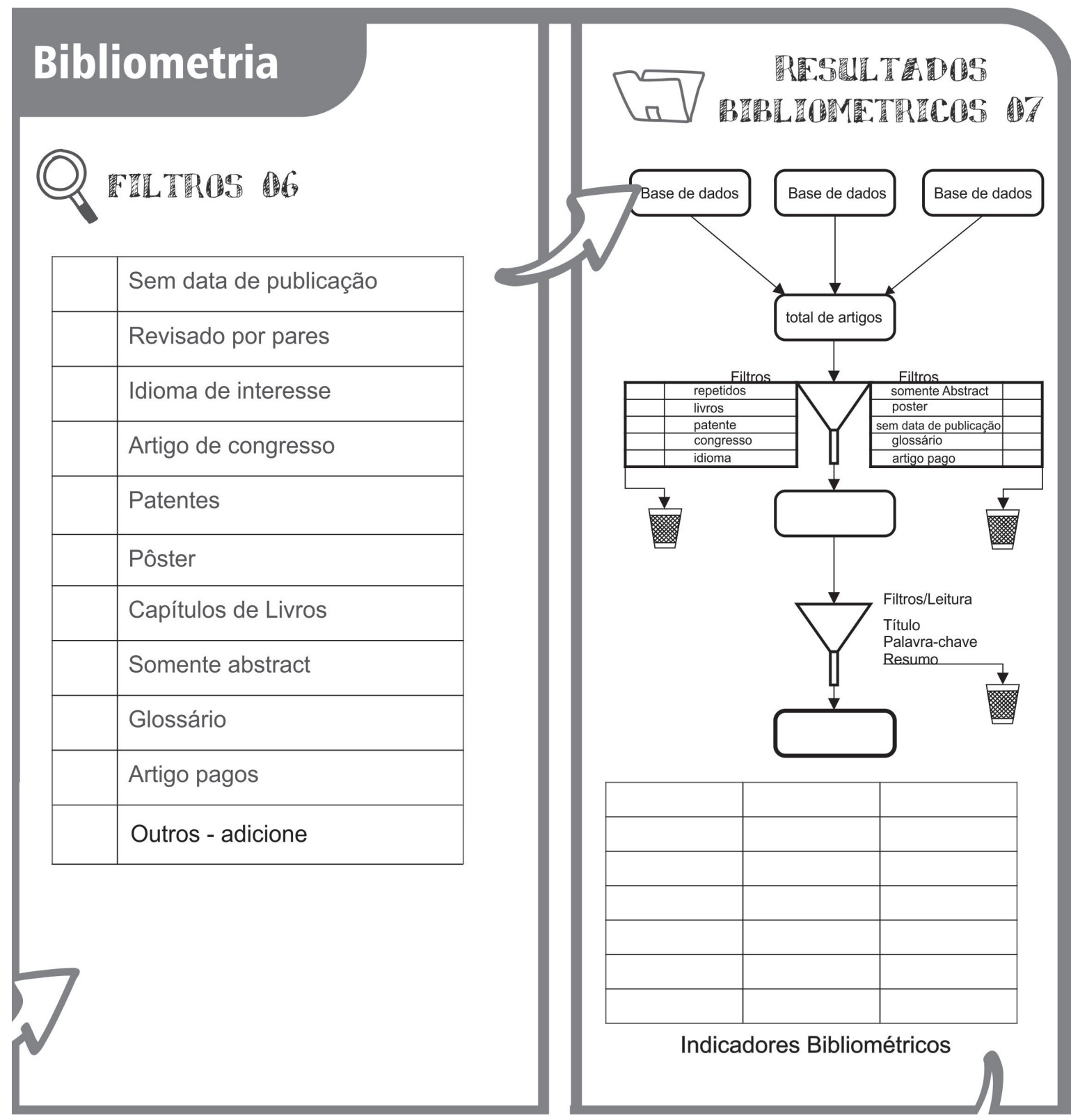

Nesses dois campos, apresentados na Figura 5, pode-se compreender melhor as etapas que dizem respeito à bibliometria. Os Filtros aqui listados são sugestões que o pesquisador pode utilizar no momento de seleção do material bibliográfico quando estiver analisando as informações obtidas das bases de dados. No campo Resultados Bibliométricos, apresenta-se um fluxograma estrutural dos resultados obtidos com o descritor, com o objetivo de representar graficamente o processo a partir da coleta de dados. A seguir, ainda nesse gráfico, encontra-se uma tabela vazia. Esta deve ser preenchida com os indicadores bibliométricos selecionados, uma descrição deles e os valores identificados para esses indicadores na pesquisa. Havendo 
falta de espaço, o quadro pode ser complementado com post-its ou outras páginas soltas.

A Figura 6 apresenta os três quadros finais do Canvas.

Figura 6 Terceira parte do Canvas

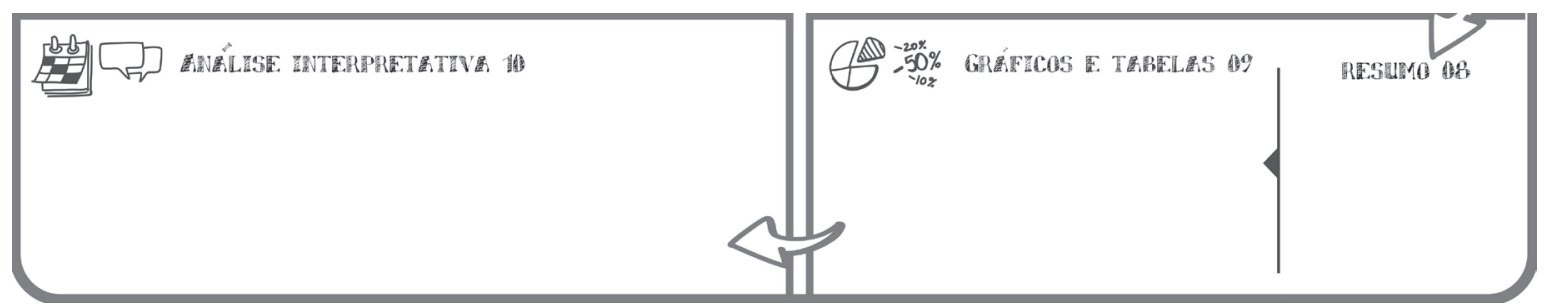

4.3 Feedback dos participantes

A avaliação dos participantes da oficina foi muito favorável, perfazendo 9,5 (de o a 10), como nota final da oficina. Diversos feedbacks foram úteis para remodelar o Canvas, bem como tornar mais compreensíveis as instruções do checklist. O principal acréscimo vindo desses feedbacks foi a inclusão do Quadro 1 - Objetivos - , no Canvas. Com este quadro, o pesquisador não perderia de vista o que ele pretende alcançar como resultados, segundo os alunos.

Também foi ressaltada a importância da oficina para o público leigo em Revisão Sistemática e Análise Bibliométrica. Todos os participantes já tinham experiência com esses procedimentos e comentaram da importância da divulgação dos mesmos, seja por oficinas especiais, seja em sala de aula com seminários ou com recursos visuais facilitadores, como o Canvas. Suas colocações pontais geraram poucas contribuições para a melhoria da ferramenta, levando em consideração que todos já faziam o uso da revisão sistemática.

\section{CONSIDERAÇÕES FINAIS}

A pesquisa científica precisa se valer de suportes confiáveis em termos de referências. Revisão sistemática e análise bibliométrica figuram, nesse contexto, como uma necessidade, uma vez que fornece para o pesquisador uma matéria-prima criteriosamente selecionada. Justifica-se investir mais na disseminação de tais procedimentos de pesquisa em áreas em que ainda não são muito difundidas, como a pesquisa em Design, bem como em formas de torná-los mais acessíveis e mais fáceis em termos de execução e compreensão de Informações. A Visualização de Informação, por sua vez, apresenta-se como um importante recurso posterior ao tratamento dos dados. Tais técnicas permitem uma compreensão intuitiva e global de informações oriundas da pesquisa, tanto para o pesquisador durante a mesma, afim 
de tomar decisões operacionais, quanto para a comunidade interessada nas publicações científicas, objetivando a melhor compreensão de achados e invenções.

Este artigo teve por objetivos apresentar um método de revisão sistemática e análise bibliométrica desenvolvido por seus autores, e fazer uso de uma técnica de representação visual a fim de facilitar a compreensão do processo desenvolvido. O método empregado nesta pesquisa, baseado em prototipar e realizar testes do método em uma oficina de extensão na UFSC se mostrou útil para alcançar os objetivos estabelecidos. Os resultados se mostraram satisfatórios, uma vez que geraram processo e instrumento para a realização de revisões sistemáticas e análises bibliométricas, e ainda formas de melhor visuallizar os resultados.

Destacam-se, como recomendações para estudos futuros:

a) Estudos sobre indicadores bibliométricos expressos tabelas na forma de painéis de controle administrativo;

b) Novas versões do instrumento de visualização de informação apresentado neste artigo, para contemplar variações metodológicas;

c) Um estudo demonstrando o valor de revisão sistemática e analise bibliométrica para a pesquisa em Design, bem como usos desses recursos para pesquisa aplicada.

\section{REFERÊNCIAS}

ARAÚJO, C. A. A. Bibliometria: evolução histórica e questões atuais. Em Questão, v. 12, n. 1, :11-32, 2006.

BROWN, Tim. Design thinking: uma metodologia poderosa para decretar o fim das velhas ideias. Rio de Janeiro: Elsevier, 2010.

Card, S. K, Mackinlay, J. D., Shneiderman, B. Readings in Information Visualization: Using Vision to Think. Morgan Kaufman Publishers, 1999.

CORREA, Renato Fernandes; VIEIRA, Jessica Monique de Lira. Representações visuais para recuperação de informação na BDTDUFPE. Perspectivas em Ciência da Informação. Recife, : 18-34. dez. 2013.

ENSSLIN, L et al. ProKnow-C: Processo de análise sistêmica. Brasil: Processo técnico com patente de registro pendente junto ao INPI, 2010.

ENSSLIN, L., GIFFHORN, E., ENSSLIN, S. R., PETRI, S. M. \& VIANNA, W. B. Avaliação do Desempenho de Empresas Terceirizadas com o Uso da Metodologia Multicritério de Apoio à Decisão- Construtivista. Revista Pesquisa Operacional, v.30, n.1, : 125-152. 2010.

GIL, Antonio Carlos. Como elaborar projetos de pesquisa. São Paulo: Atlas, 2002. GIL, Antônio Carlos. Métodos e Técnicas de Pesquisa Social. São Paulo: Atlas, 2008. GRÁCIO, M. C. C.; OLIVEIRA, E. F. T. Produção e comunicação da Informação em CT\&I, GT7 da ANCIB: análise bibliométrica no período de 2003 a 2009. Liinc em Revista, Rio de Janeiro, v. 7, n. 1, p. 248-263, mar. 2011. Disponível em: <http://revista.ibict.br/liinc/index.php/liinc/article/viewFile/412/289>. Acesso em: 13 mar. 20 
Journal Metrics. Frequently asked questions. Disponível em: <http://www. journalmetrics.com/faq.php> Acesso em 19 de dezembro de 2014.

LACERDA, R. T.; ENSSLIN, L.; ENSSLIN, S. R.. Uma análise bibliométrica da literatura sobre estratégia e avaliação de desempenho. Gestão da Produção, Sao Carlos, v. 9, n. 1, :59-78, nov. 2012.

MARCONI, Marina de A. \& LAKATOS, Eva. M. Fundamentos da Metodologia Científica. São Paulo: Atlas, 2003.

NARIN, Francis. Evaluative bibliometrics: the use of publication and citation analysis in the evaluation of scientific activity. Cherry Hill, N. J.: Computer Horizons, 1976

OSTERWALDER, A.; PIGNEUR, Y.. Business Model Generation. New Jersey - Usa: (john Wiley \& Sons, Eds, 2010. 278:.

PAO, M. L. Concepts of information retrieval. Englewood, Colorado:Libraries Unlimited, Inc., 1989. 285:

PIRES, Eduardo Menezes; QUEIROZ, Ruy Guerra de. Consolidando o Business Model Framework: Estratégia de crescimento e competitividade na metodologia Business Model Generation. 2012. 74 f. Monografia (Especialização) - Curso de Computação, Centro de Informática, Ufpe, Recife, 2012.

SAMPAIO, R. F., MANCINI, M. C. Estudos de Revisão Sistemática: Um Guia Para Síntese Criteriosa Da Evidência Científica. Revista brasileira de fisioterapia, São Carlos, v. 11, n. 1, : 83-89, jan./fev. 2007.

Scielo - Scientific Eletronic Library On Line. Disponível em: <http://www.scielo. $\mathrm{br} /$ scielo.php?script=sci_serial\&pid=0101-7438\&nrm=iso\&rep=\&lng=pt $>$ acesso em 20 de dezembro de 2014.

SOUZA, D. K.. Utilização de Técnicas de Visualização para a Recomendação de Substitutos. 2008. 112 f. Dissertação (Mestrado) - Curso de Programa de Engenharia de Sistemas e Computação, Cope, Ufrj, Rio de Janeiro, 2008.

TAGUE-SUTCLIFFE, J. An introduction to informetrics. Information Processing \& Management, v. 28, n. 1, p. 1-3, 1992.

TÁPANES, G.T. L. e ALFONSO, O. G.; Estudio bibliométrico de la Revista CorSalud. Revista Biblios, $\mathrm{n}{ }^{\circ}$ 52, 2013. DOI: http://dx.doi.org/10.5195/biblios.2013.126

VIEIRA, Jessica Monique de Lira; CORREA, Renato Fernandes. VISUALIZAÇÃO DA INFORMAÇÃO NA CONSTRUÇÃO DE INTERFACES AMIGÁVEIS PARA SISTEMAS DE RECUPERAÇÃO DE INFORMAÇÃO. Revista Eletrônica de Biblioteconomia e Ciência da Informação, Recife, v. 13, n. 32, p.73-93, 2011. 


\section{Sobre os autores}

\section{Ivan Luiz de Medeiros}

Doutorando, Programa de Pós-Graduação em Design - UFSC.

<Ivan.medeiros@ufsc.br>

\section{Alessandro Vieira}

Mestrando, Programa de Pós-Graduação em Design - UFSC.

<alessandro.v.r@posgrad.ufsc.br>

\section{Gilson Braviano}

Professor Doutor, Programa de Pós-Graduação em Design - UFSC.

<gilson@cce.ufsc.br>

\section{Berenice Santos Gonçalves}

Professora Doutora, Programa de Pós-Graduação em Design - UFSC.

<berenice@cce.ufsc.br>

Artigo recebido em 07 jan. 2014,

aprovado em 18 mai. 2014. 